Research Article

\title{
Mechanical Performance of Eco-Friendly Sandwich Wall with Rice Husk Recycled Concrete
}

\author{
Dingshi Chen $\mathbb{D}^{1,2}$ Maohua Du, ${ }^{3}$ Yubin Tian $\mathbb{D}^{1},{ }^{1,4}$ and Wenmiao $\mathrm{Du}^{5}$ \\ ${ }^{1}$ Key Lab of Structures Dynamic Behavior and Control of the Ministry of Education, Harbin Institute of Technology, \\ Harbin 150090, China \\ ${ }^{2}$ Bridge Design Institute, CCCC First Highway Consultants Co., Ltd., Xi'an 710075, China \\ ${ }^{3}$ Ordnance Engineering College, Naval University of Engineering, Wuhan 430033, China \\ ${ }^{4}$ Key Lab of Smart Prevention and Mitigation of Civil Engineering Disasters of the Ministry of Industry and \\ Information Technology, Harbin Institute of Technology, Harbin 150090, China \\ ${ }^{5}$ Wuhan Arnova Architectural and Engineering Design Firm Co., Ltd., Wuhan 430074, China \\ Correspondence should be addressed to Yubin Tian; tianyubin@hit.edu.cn
}

Received 8 December 2020; Revised 21 January 2021; Accepted 2 February 2021; Published 8 March 2021

Academic Editor: Zhigang Zhang

Copyright (C) 2021 Dingshi Chen et al. This is an open access article distributed under the Creative Commons Attribution License, which permits unrestricted use, distribution, and reproduction in any medium, provided the original work is properly cited.

In the construction industry, an approach to alleviate the environmental problem is to apply ecological composite materials to the construction field. In this paper, the authors added the recycled aggregate and the rice husks to the concrete and measured the strengths of rich husk recycled concrete (RHRC) with different factors as well as determined the constitutive model. Subsequently, the flexural experiment of RHRC sandwich wall was carried out and analyzed in detail, which proved that it could bear the wind loads in normal use condition by the calculation of the experimental data. Then, the compressive experiment and analyses were conducted similarly. Moreover, the finite element method was applied to study the influence of tie bars on the flexural bearing capacity and to deduce the simplified calculation method of vertical bearing capacity of RHRC walls.

\section{Introduction}

The construction industry consumes more raw materials than other social activities, leading to the depletion of natural resources and the production of construction waste $[1,2]$. It is suggested that one of the most effective ways to reduce building resource consumption and achieve sustainable building practices is to use recycled materials made from waste and renewable materials [3-5]. Among sustainable materials, ecological composite materials are increasingly concentrated because of their advantages, such as reuse of waste, low overall impacts on the environment, and biodegradability and nontoxicity $[6,7]$.

Nowadays, more and more scholars are committed to the application of ecological composite materials in the field of architecture. For example, woven fabric waste and red mud of aluminium production waste, waste plastic, glass waste, etc. have been studied and proved to be feasible for the application and development of the construction materials made from them, and the utilization of the materials can undoubtedly reduce the consumption of resources [8-11]. Particularly for the walls, which exist in traditional buildings abundantly, they should be advocated to use this kind of material. Leshina et al. studied the effect of glass waste on the properties of ceramic wall materials and demonstrated that the domestic waste glass can be applied to the wall [12]. For the purpose of building energy-saving, Ji et al. prepared a novel one-piece wall ceramic board by using fly ash and ceramic waste which indicated it could efficiently reduce the thermal bridges and exert excellent energy conservation effect [13]. Furthermore, the researches on the material characteristics of lightweight concrete blocks with miscanthus from the perspective of compressive strength and heat conductivity proved that it could meet the requirements of use [14]. Hou et al. put forward a three-level mechanical model of ecological composite walls based on their structural 
characteristics, mechanical properties, and collaborative performance, and the results manifested that the structure possessed several seismic defending lines and had good seismic performance [15].

In addition to materials made from aforesaid waste, the exploitation of building materials based on agricultural waste has also received increasing attention, due to the environmental problems caused by the large-scale generation of such waste and the difficulty of treatment [16]. At present, agricultural waste could be used as building materials to achieve the cyclic utilization of resources and meet the requirements of building functions [17]. For example, waste from hemp production process could be used to make high sound absorption muffling walls [18], as well as rice straw and maize husk could be used as insulation material for precast concrete Sandwich wall [19]. Among the various agricultural wastes, rice husk occupies a large proportion of agricultural waste and has a better resistance to molds in comparison with other plant fibre composites [20]. António et al. proposed a new composite material incorporating rice husk intended for construction applications and elaborated an experimental study on the mechanical, thermal, and acoustic performance of new composite boards made of rice husk waste. The results suggested that optimized construction solutions based on these composite materials could improve the performance of thermal and sound insulation of buildings [21]. Liu et al. used control variable method to systematically study the concrete with different particle sizes and different contents of rice husks to provide corresponding technology for supporting the preparation of highperformance walls [22]. Zhao studied the stressing state and failure criterion of rice husk mortar composite wall based on the theory of stressing state of the structure, which analyzed the influences of loading mode and holing mode on the stressing state and failure load of the wall [23]. The above researches show that concrete mixed with rice husks performs well in mechanical properties, thermal, and sound insulation functions, which has positive effects on sustainable development and is worthy of promotion.

Although the above researches have discussed many properties and applications of the ecological composite walls, almost all about heat and sound insulation, there are few researches on the mechanical properties of them. This is not conducive to determine the bearing capacity of the ecological composite walls and to promote them as loadbearing components widely, resulting in its narrow application. The restrictions to the development and application of the ecological composite wall are because of not only the insufficient researches on the wall itself but also its basic component materials. There is still a lack of further and more comprehensive research on mechanical properties and its influence factors of ecological composite materials. These problems indicate that the mechanical properties of ecological composite materials and the wall need further research to develop its potential for application and promotion.

This paper makes efforts to study the mechanical properties of ecological composite material, rice husk recycled concrete (RHRC), and RHRC walls. The compressive strength of different rice husk content and recycled aggregate replacement rate were tested. Meanwhile, the constitutive curves and its model of RHRC were determined, according to the mechanical property tests of RHRC. In order to ensure the wind load resistance of the sandwich walls made of RHRC, the flexural experiment of it was carried out, and the cracking load, bearing capacity, and flexural deformation of it were recorded and analyzed. Similarly, the compressive experiments of the wall with and without a hole were also conducted to verify the vertical bearing capacity. In addition, based on the finite element method, the influence of the tie bar on the flexural bearing capacity was studied and the simplified calculation method of the vertical bearing capacity considering the "mid-shift" effect was evolved.

\section{Experimental Study on Mechanical Properties of RHRC}

2.1. Materials and Mix Proportions. Portland cement (P. O. 42.5) was used as the binders of RHRC, and the rebound test strength and particle size of the recycled aggregate are, respectively, $37.5 \mathrm{MPa}$ and $5-15 \mathrm{~mm}$. The chemical composition of rice husks is listed in Table 1. In order to study the influence of the rice husk content and recycled aggregate replacement rate on the mechanical properties of RHRC and to reduce the influence of other factors, this test was carried out on nine groups of blocks with the water-cement ratio and the content of admixture unchanged. The rice husk contents were $0 \%, 20 \%$, and $30 \%$ by mass of cement, and recycled aggregate replacement rates were $0 \%, 30 \%, 50 \%$, and $100 \%$, respectively. Furthermore, rice husks had certain water absorption capacity, so the actual water consumption of RHRC was composed of the net one of concrete and additional one of rice husks. The water absorption of rice husks was measured before the formal test. The rice husk of a certain quality was soaked in water, and the quality of the rice husk was weighed after water absorption and saturation. Compare the mass values before and after soaking to calculate the moisture content. The results showed that, with the increase of $1 \mathrm{~g}$ rice husk, the additional water consumption of rice husk increased by $1.5 \mathrm{~g}$. According to the preliminary test, the mixing ratio of rice husk recycled concrete (RHRC) was determined as water: cement: sand: stone $=180: 480: 650: 1050$. In addition, the actual content of amine superplasticizer was $1.5 \%$ of the quality of cement. The amine superplasticizer, silica densifier, and silica fume were mixed in ratio of $1: 4: 3$ to improve the impermeability, compressive, and bending resistance of concrete.

2.2. Wall Making and Reinforcement Layout. The main materials of the wall are the RHRC, steel bars, benzene plate, and galvanized welded mesh. Meanwhile, the size of the specimen and the arrangement of steel bars are shown in Figure 1. The detailed preparation method of the specimen is as follows. First, use wood boards to support the template outside the frame. Cover the bottom of the formwork with galvanized wire mesh on the pad. Put the girder, column 
Table 1: Chemical composition of rice husks (\%).

Chemical composition

Crude fibers

Xylogen

Poly pentosan

Ash content

Water

Crude protein

Ether extract
Content (\%)

$35.5-45.0$

$21.0-22.2$

$16.0-22.2$

$13.0-22.0$

$7.5-16.0$

$2.5-3.0$

$0.7-1.3$

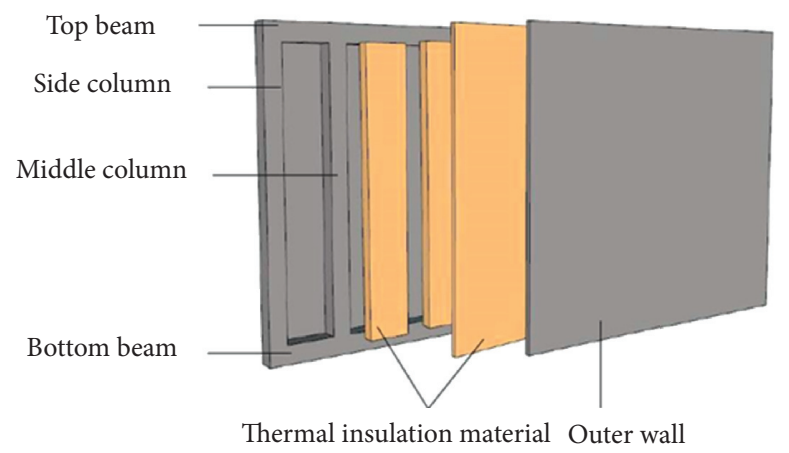

(a)

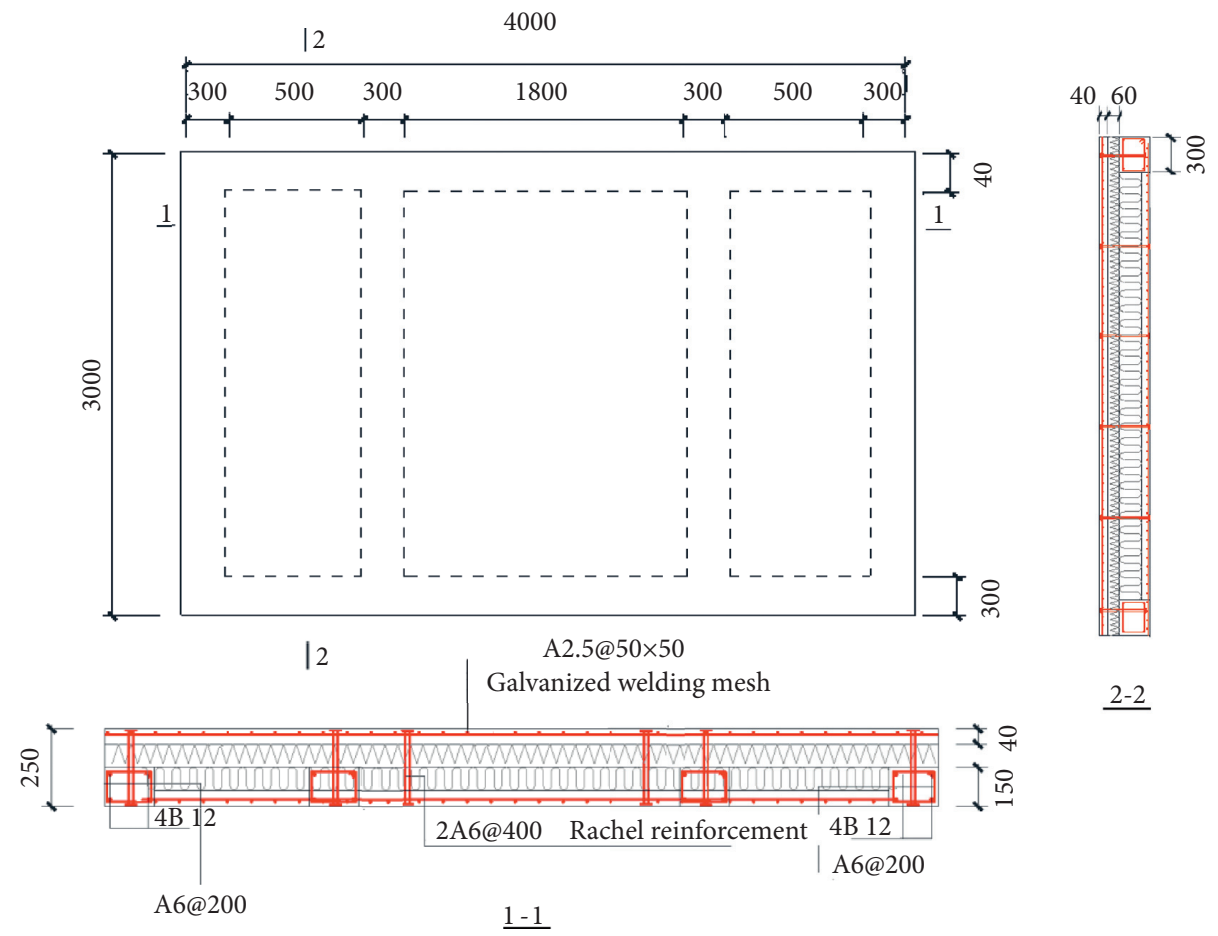

(b)

Figure 1: Continued. 


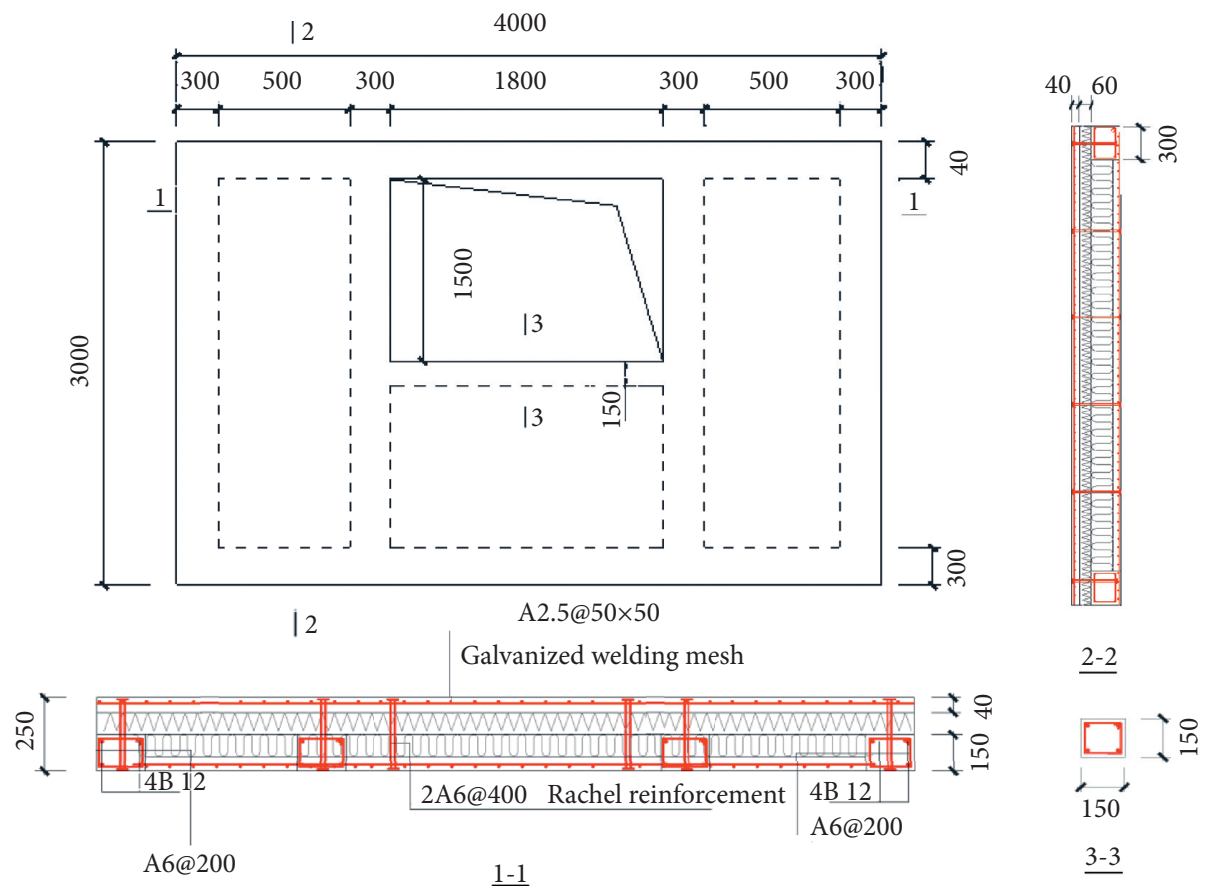

(c)

FIGURE 1: The structure of the RHRC Sandwich wall: (a) the composition of the wall; specimen size and reinforcement of the wall (b) without a hole and (c) with a hole.

longitudinal bars and stirrups into the template of the inner frame of the girder and column. Subsequently, the inner and outer leaf wall drawing bars were arranged and the strain gauges were pasted to lead the wire and waterproof treatment was done well. The inner leaf wall would be poured immediately after the layout was completed. When the inner wall concrete had a certain strength, remove the inner frame of the formwork and install the benzene plate. Finally, the outer leaf wall was covered with galvanized welding mesh and the outer leaf wall was poured and maintained.

The arrangement of steel bars for the wall is shown in the Figures 1(b) and 1(c). The average yield strength and ultimate strength of $12 \mathrm{~mm}$ diameter HRB400 threaded steel bars are, respectively, $422 \mathrm{MPa}$ and $610 \mathrm{MPa}$ and those of $6 \mathrm{~mm}$ diameter HPB300 threaded steel bars are, respectively, $303 \mathrm{MPa}$ and $407 \mathrm{MPa}$. The galvanized welding mesh is made of Q235 steel, and the yield strength and ultimate strength are $214 \mathrm{MPa}$ and $277 \mathrm{MPa}$. The elastic modulus of HPB300 steel bar is $2.1 \times 10^{5} \mathrm{~N} / \mathrm{mm}^{2}$, the elastic modulus of HRB400 steel bar is $2.0 \times 10^{5} \mathrm{~N} / \mathrm{mm}^{2}$, and the elastic modulus of Q235 galvanized welded mesh is $2.0 \times 10^{5} \mathrm{~N} /$ $\mathrm{mm}^{2}$.

2.3. Loading Scheme and Measuring Point Layout. The large size and the high bearing capacity outside the plane of the test wall results in not being suitable to use the heavy loads to simulate the uniform loads. Therefore, the steel beams are used to transform the loads applied by the counterforce device into four concentrated loads, as shown in Figure 2. The four distribution beams are divided into two groups, and

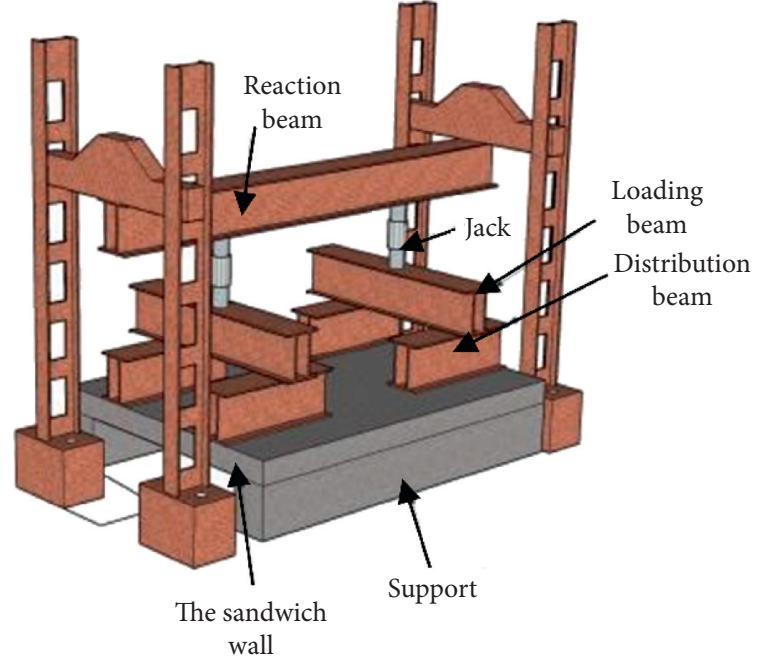

FIGURE 2: The loading device for bending performance experiment.

the two groups of distribution beams are arranged longitudinally at $100 \mathrm{~mm}$ from the left and right ends of the sandwich wall. The two distribution beams of each group are symmetrically arranged at the positions of $1 / 4$ and $3 / 4$ of the transverse direction of the sandwich wall. The two ends of the test piece in this test are directly placed on the support. In this bending performance test, the reaction device made of four reaction frames and one steel beam is used to simulate the uniformly distributed load through two distribution beams and four loading beams with two jacks. The preloading was firstly carried out to check the instrument and to 
eliminate the installation gap, and then the loads were applied with $20 \mathrm{kN}$ as fixed increment. The arrangements of the strain gauges on steel reinforcements (on the left) and in concrete (on the right) as well as of the displacement meters are shown in Figure 3.

In this experiment, one wall has a hole of $1800 \mathrm{~mm} \times 1500 \mathrm{~mm}$ and the other one has no hole, and the other sizes were same as the aforesaid one. The vertical bearing capacity was estimated to be $3200 \mathrm{kN}$, and the loads applied by a four-axis compression machine were transmitted to the top beam, as shown in Figure 4. The single jack applied the load of $50 \mathrm{kN}$ at each step and then held the load for $5 \mathrm{~min}$ to record the strains and vertical and lateral displacements of the plate and to observe the development of cracks. When the estimated failure load was about to be reached, it was changed to $30 \mathrm{kN}$ each step until the experimental wall failed.

The layouts of displacement meters and the strain gauges are shown in Figure 5. For the wall with a hole, the measurements of steel and concrete are the same as those of the wall without a hole.

During the loading process, when cracks appeared on the surface of the inner wall and the strain values of concrete exceeded the ultimate tensile strain, the load would be determined to be the cracking load of the inner wall. The bearing capacity was measured in accordance with the provisions of "Standard Methods for Testing of Concrete Structures” (GB/T 50152-2012) [24].

\section{Result and Discussion}

3.1. Research on RHRC Test Strength. All the test blocks were maintained for 28 days under standard conditions, and the loading device was $200 \mathrm{t}$ pressure testing machine. The cubic compressive strength test is performed on the cubic test blocks with the size of $100 \mathrm{~mm}$ in accordance with GB/T 50081-2002 [25]. Strain and displacement gauges were arranged on both sides of the test blocks to measure the strains before and after the failure of the specimens, respectively. At the initial stage of loading, steel supports were separated from the top of the compression machine. When the load reached about $70 \%$ of the ultimate load, the steel supports were adjusted to make them contact with the top of the compression machine.

According to Chinese code-Standard for test method of mechanical properties on ordinary concrete (GB/T 50081-2002), concrete specimens were made. Then, we put it in a standard curing room with a temperature of $20 \pm 2^{\circ} \mathrm{C}$ and a relative humidity of $95 \%$ or more. Preliminary tests have determined the mix ratio of RHRC to be: water: cement: sand: stone $=180: 480: 650: 1050$. More information has been provided in Table 2, including the number of specimens, types, and detailed mixing ratio of each specimen. As shown in Table 2, the rice husks lowered the cubic compressive strength of concrete, and the higher the rice husk content was, the lower the strength was. The recycled aggregate also affected the strength, which decreased with the increase of the replacement rate of recycled aggregate before $50 \%$ and then increased until $100 \%$. However, when the replacement rate was up to $100 \%$, the strength was lower than that without recycled aggregate. The changing features of the prismatic compressive strength with the replacement rate of recycled aggregate was similar to the cubic one, but the critical value of the replacement rate between the reduction and increase of the compressive strength was $30 \%$ instead of $50 \%$. In addition, the recycled aggregate replacement rate was taken as a single variable in Groups 2, 3, 4 , and 5, and the content of rice husk was taken in Groups 1, 2 , and 6. By comparing the experimental data of these two parts shown in Table 2, it can be detected that the influence of rice husk content on concrete strength was greater than that of replacement rate of recycled aggregate.

In addition to the strength of RHRC material, equivalent carbon saving is another important factor affecting its popularization and application. Using the calculation method of carbon dioxide emission proposed by Jianzhuang [26] and Yuxing [27] et al., the carbon dioxide emission of producing 1 cubic meter of recycled concrete was obtained. As the carbon emission from the production of cement is much larger than that of recycled aggregate, the carbon conservation generated by recycled aggregate is negligible as a whole. Hence, the main factor affecting carbon conservation is the amount of rice husk. When the content of rice husk is $20 \%$ and $30 \%$, carbon dioxide emissions are reduced by $4.4 \%$ and $6.6 \%$, respectively, which has better environmental value in terms of reducing carbon dioxide emissions. Therefore, it is of great significance to study its mechanical properties and lay a foundation for its wide application.

\subsection{Experimental Results of Stress-Strain Relationship.}

The compression constitutive curve of concrete usually consists of two parts, and there is a descending section after the peak stress is reached. The ascending section of the constitutive curve is directly determined by the strain collected by the strain gauges, while the descending section is calculated by the displacement values measured by the displacement meters according to the following equation:

$$
\sigma=\frac{N}{A} ; \varepsilon=\frac{\Delta l}{l}
$$

where $\sigma$ is the stress of concrete; $N$ is the axial force applied by pressure testing machine; $A$ is the cross-sectional area; $\varepsilon$ is the strain of concrete; and $l$ is a third of the length of the prism.

In order to better study the stress-strain curve, a curve with relatively complete shape is selected from each group of specimens for dimensionless analysis shown in Figure 6. The horizontal coordinate is represented by the strain divided by the peak strain $\varepsilon / \varepsilon_{r}$ and the vertical coordinate by the stress divided by the peak stress $\sigma / \sigma_{r}$.

As deduced from Figure 6, the stress-strain curves of RHRC are similar to that of ordinary concrete, which could be divided into the following four stages:

(1) Elastic Stage. Compared with the ordinary concrete, the addition of rice husk and recycled aggregate in RHRC affected the bond behavior. When the stress 


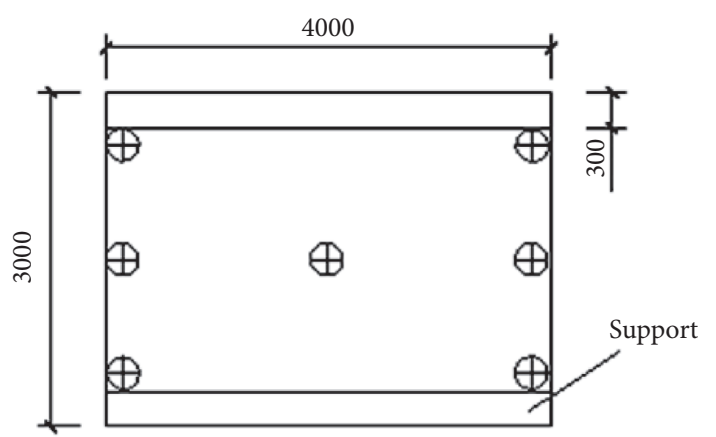

(a)

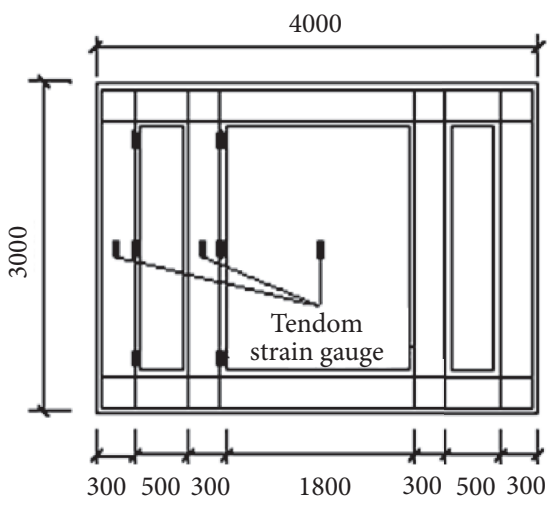

(c)

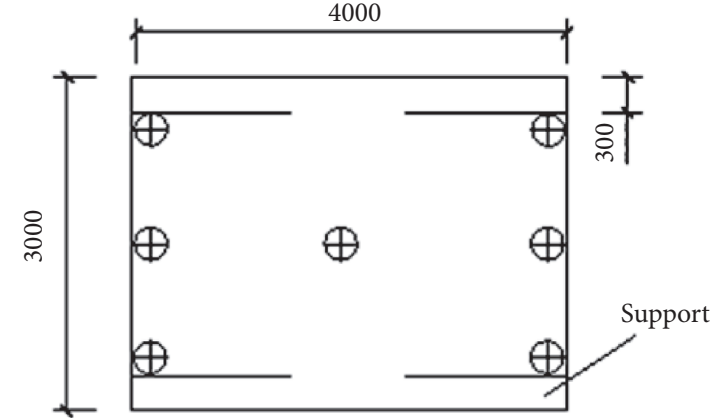

(b)

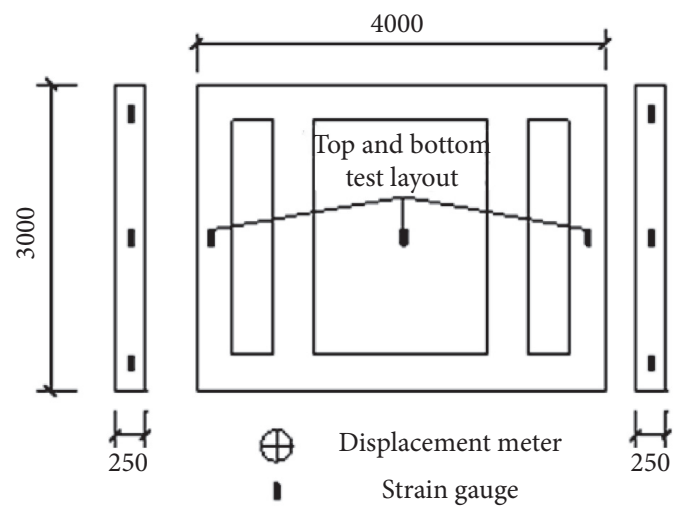

(d)

Figure 3: The arrangement of strain gauges and displacement meters (dimensions in mm): layout of the displacement meter on (a) the top of the specimen and (b) the bottom of the specimen; (c) rebar strain measurement point layout; and (d) layout of concrete strain measuring points.

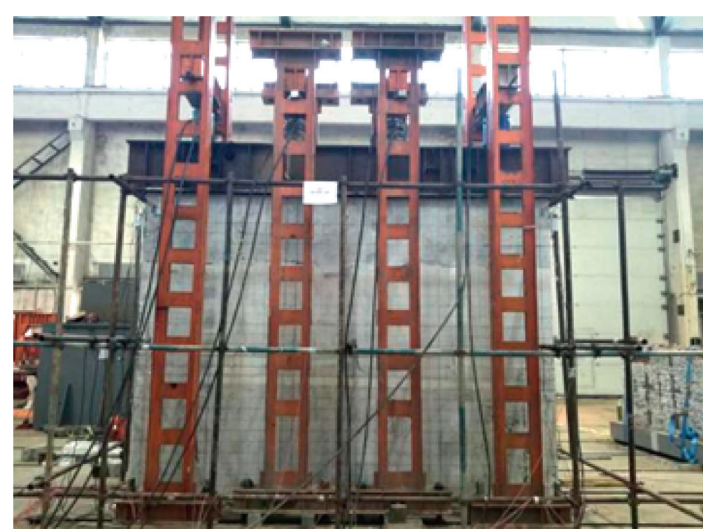

FIGURE 4: The loading device of the compressive experiment.

was less than $60 \%-80 \%$ of the peak stress, the constitutive curve was almost straight, which meant that the stress increased in proportion to the strain.

(2) Fracture Development Stage. From the end of the elastic phase to the peak stress point, RHRC began to enter plasticity and microcracks appeared. With the increase of stress, short and fine cracks began to connect and expand gradually, and the plastic deformations increased as well.
(3) Fracture Instability Propagation Stage. When the stress exceeded the peak stress values, the curves began to decline. It could be seen from the dimensionless constitutive curves that the descending section of RHRC was relatively gentle compared with ordinary concrete and more gently with the increase of rice husk content. When the loads overpassed the failure loads, oblique cracks appeared along the surface of the prisms in the direction close to $45^{\circ}$.

(4) Failure Stage. The test blocks presented shear failure and the curves gradually flattened along with the increase of vertical deformation.

Based on the experiment, the constitutive model of RHRC is abstracted by comparing with the stress-strain relationship adopted by European code [28] and with that proposed by Guo [29].

The equation in the European code is

$$
y=\frac{K x-x^{2}}{1+(K-2) x} .
$$

The piecewise function proposed by Guo is as follows:

$$
\begin{aligned}
& y=a x+(3-2 a) x^{2}+(a-2) x^{3}, \quad 0<x<1, \\
& y=\frac{x}{b(x-1)^{2}+x} .
\end{aligned}
$$




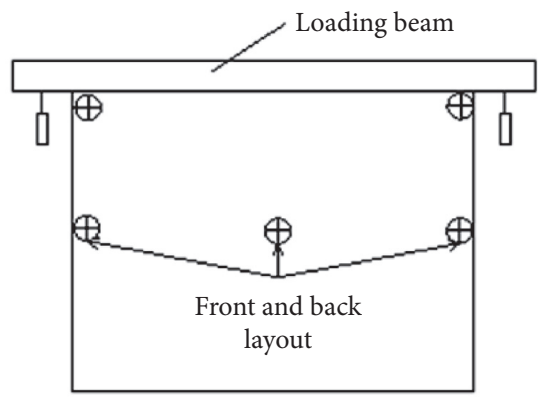

(a)

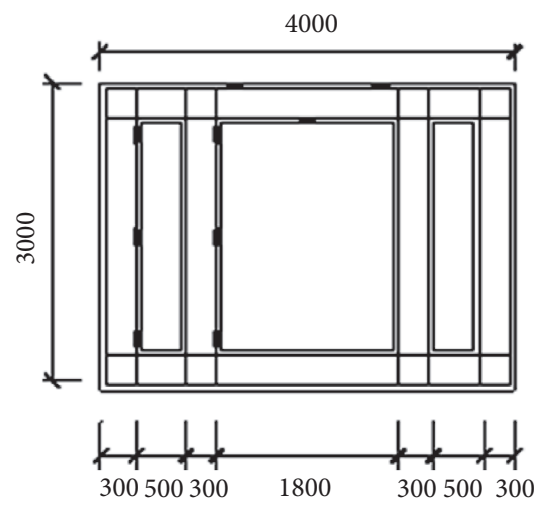

(c)

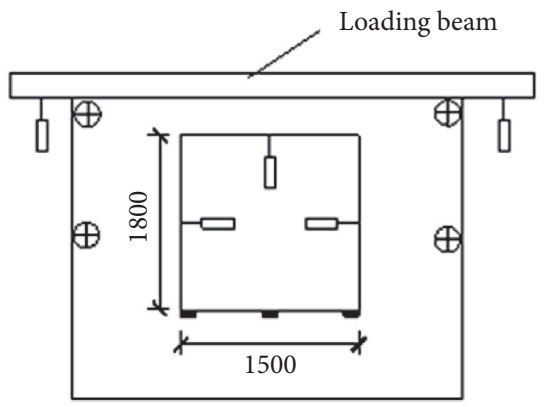

(b)

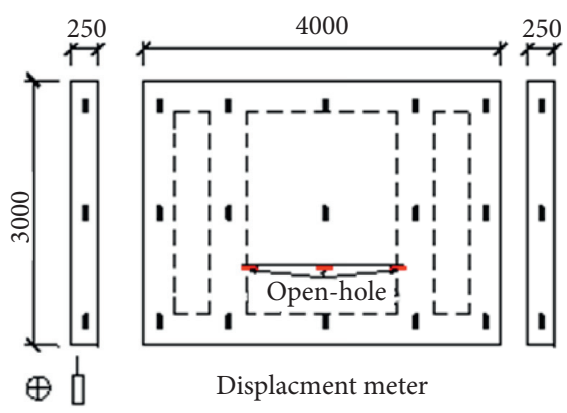

I Displacment gauge with both

Displacment gauge with unique

- arrangement for open-hole specimen

(d)

Figure 5: The arrangement of strain gauges and displacement meters (dimensions in $\mathrm{mm}$ ): (a) displacement gauges layout of specimen without an opening hole; (b) the opening hole specimen displacement gauges; (c) layout of strain gauge measuring points for steel bars; (d) layout of concrete strain gauges for specimens with or without a hole.

TABLE 2: Size and experimental results of the specimens.

\begin{tabular}{|c|c|c|c|c|c|c|}
\hline Group & $\begin{array}{c}\text { Rice husk content } \\
(\%)\end{array}$ & $\begin{array}{c}\text { Replacement rate of recycled } \\
\text { aggregate }(\%)\end{array}$ & Size $(\mathrm{mm})$ & $\begin{array}{c}\text { Number of } \\
\text { specimens }\end{array}$ & $\begin{array}{l}\text { Peak stress } \\
(\mathrm{MPa})\end{array}$ & $\begin{array}{l}\text { Prismatic peak strain } \\
(\mu \varepsilon)\end{array}$ \\
\hline \multirow{2}{*}{1} & \multirow{2}{*}{0} & \multirow{2}{*}{ e } & $100 \times 100 \times 100$ & 3 & 35.4 & 1 \\
\hline & & & $100 \times 100 \times 300$ & 6 & 36.9 & 2248 \\
\hline \multirow{2}{*}{2} & \multirow{2}{*}{20} & \multirow{2}{*}{0} & $100 \times 100 \times 100$ & 3 & 27.3 & 1 \\
\hline & & & $100 \times 100 \times 300$ & 6 & 20.5 & 2298 \\
\hline \multirow{2}{*}{3} & \multirow{2}{*}{20} & \multirow{2}{*}{30} & $100 \times 100 \times 100$ & 3 & 21.6 & 1 \\
\hline & & & $100 \times 100 \times 300$ & 6 & 16.8 & 2368 \\
\hline \multirow{2}{*}{4} & \multirow{2}{*}{20} & \multirow{2}{*}{50} & $100 \times 100 \times 100$ & 3 & 21.5 & 1 \\
\hline & & & $100 \times 100 \times 300$ & 6 & 17.1 & 2529 \\
\hline \multirow{2}{*}{5} & \multirow{2}{*}{20} & \multirow{2}{*}{100} & $100 \times 100 \times 100$ & 3 & 23.9 & 1 \\
\hline & & & $100 \times 100 \times 300$ & 6 & 21.7 & 2116 \\
\hline \multirow{2}{*}{6} & \multirow{2}{*}{30} & \multirow{2}{*}{0} & $100 \times 100 \times 100$ & 3 & 8.8 & 1 \\
\hline & & & $100 \times 100 \times 300$ & 6 & 8.3 & 1848 \\
\hline \multirow[b]{2}{*}{7} & \multirow[b]{2}{*}{30} & \multirow{2}{*}{30} & $100 \times 100 \times 100$ & 3 & 7.4 & 1 \\
\hline & & & $100 \times 100 \times 300$ & 6 & 5.8 & 1993 \\
\hline \multirow{2}{*}{8} & \multirow{2}{*}{30} & \multirow{2}{*}{50} & $100 \times 100 \times 100$ & 3 & 6.2 & 1 \\
\hline & & & $100 \times 100 \times 300$ & 6 & 6.1 & 2657 \\
\hline \multirow{2}{*}{9} & \multirow{2}{*}{30} & \multirow{2}{*}{100} & $100 \times 100 \times 100$ & 3 & 7.5 & 1 \\
\hline & & & $100 \times 100 \times 300$ & 6 & 7.2 & 2763 \\
\hline
\end{tabular}

The testing constitutive curve of the fifth group and the aforesaid two curves are shown in Figure 7. In the ascending segment, $K=2.5497$ and $a=2.4312$, and in the descending segment, $K=3.7488$ and $b=0.5718$.
According to the comparison, the error of the descending sections between European code and the test curve is too large. But the constitutive curve proposed by Guo is almost consistent with the test results, which could be 

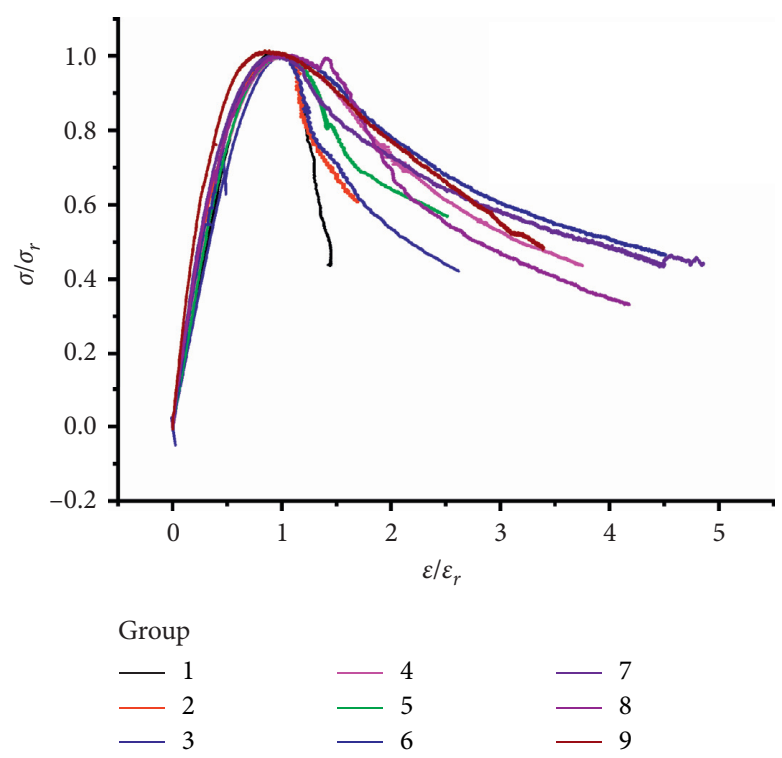

FIgURE 6: Dimensionless stress-strain curves of RHRC.

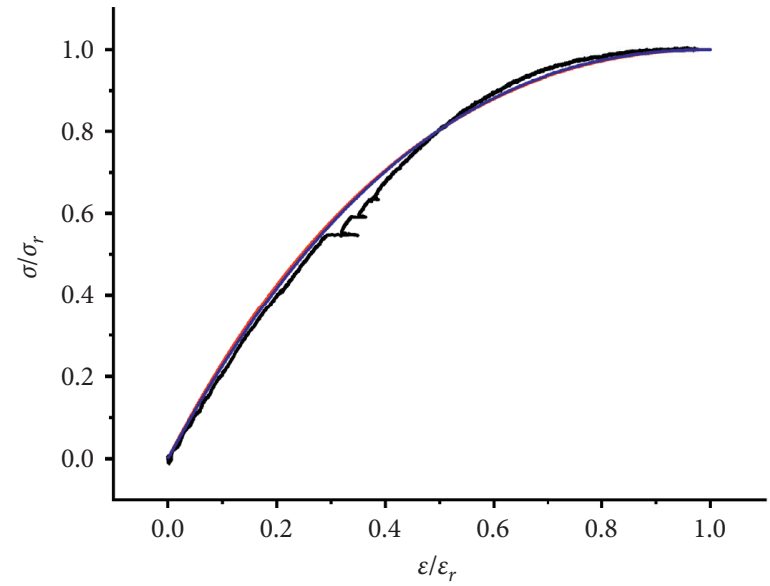

Experimental data
_ European code
Curve proposed by Guo

(a)

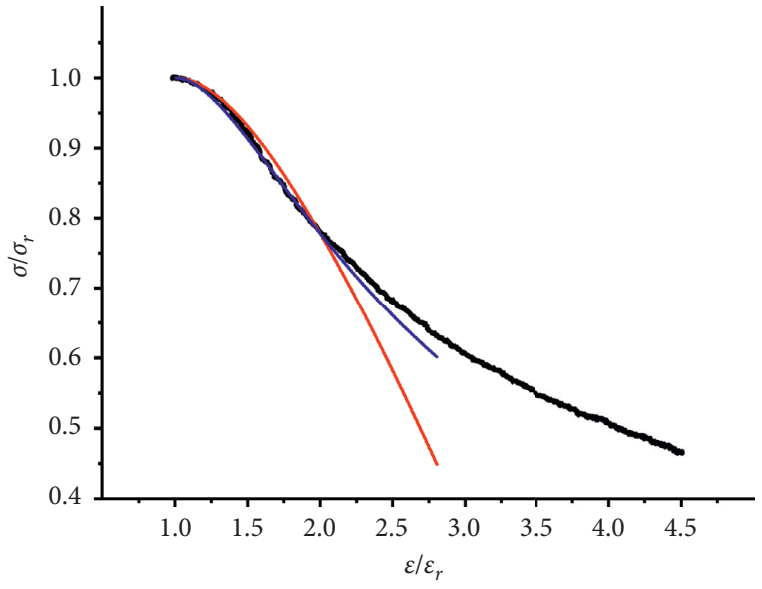

- Experimental data

- European code

- Curve proposed by Guo

(b)

FIgURE 7: Comparison of constitutive curves of concrete: (a) The ascending section and (b) the descending section of the constitutive curves.

used to describe the stress-strain curve relationship of RHRC.

Under the condition of water-cement ratio of 0.375 in this test, the relationship of parameter $b$, rice husk content $m$, and recycled aggregate replacement rate $p$ is calculated as follows:

$$
\begin{aligned}
b= & 1.523+2.467 m+1.873 p+19.043 m^{2}+0.232 p^{2} \\
& +7.355 m p .
\end{aligned}
$$

3.3. Analysis of Bending Experimental Phenomenon and Result. The early stage of loading was the elastic working stage while the strain and the deflection of the experimental wall tended to be linearly growing. There were no obvious cracking signs until the total load reached $80 \mathrm{kN}$. Thereafter, the concrete at the bottom of the inner wall began to appear the vertical microfracture with a width less than $0.1 \mathrm{~mm}$ presenting a slow development. When the total load reached $200 \mathrm{kN}$, the wire mesh yielded under tension and the cracks in the concrete of inner wall became longer and wider, as shown in Figure 8(a). In addition, at the middle position of the wall, a penetrating crack with width of $0.1 \mathrm{~mm}$ appeared along the span direction shown in Figure 8(b).

In order to study the transfer and distribution of the force in the new ecological composite sandwich wall under the load out-of-plane, the load-strain relationships of tie bars and the tensile bar of the inner wall are shown in Figure 9. It 


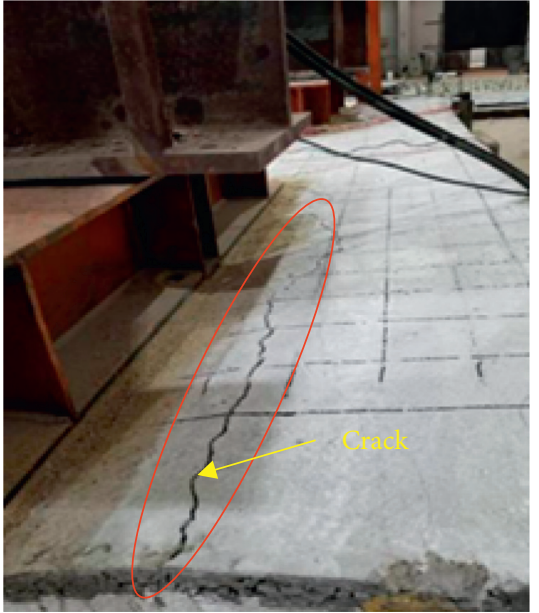

(a)

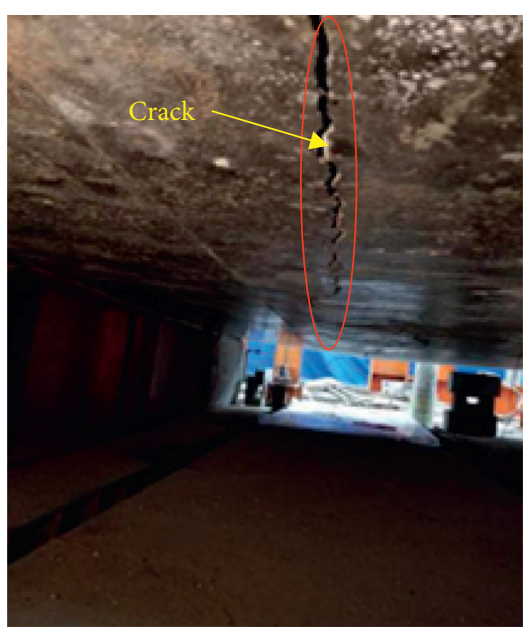

(b)

FIGURE 8: The cracks in the wall during the experiment: (a) the crack in the position of the loading beam; (b) the penetrating crack in the experimental wall.

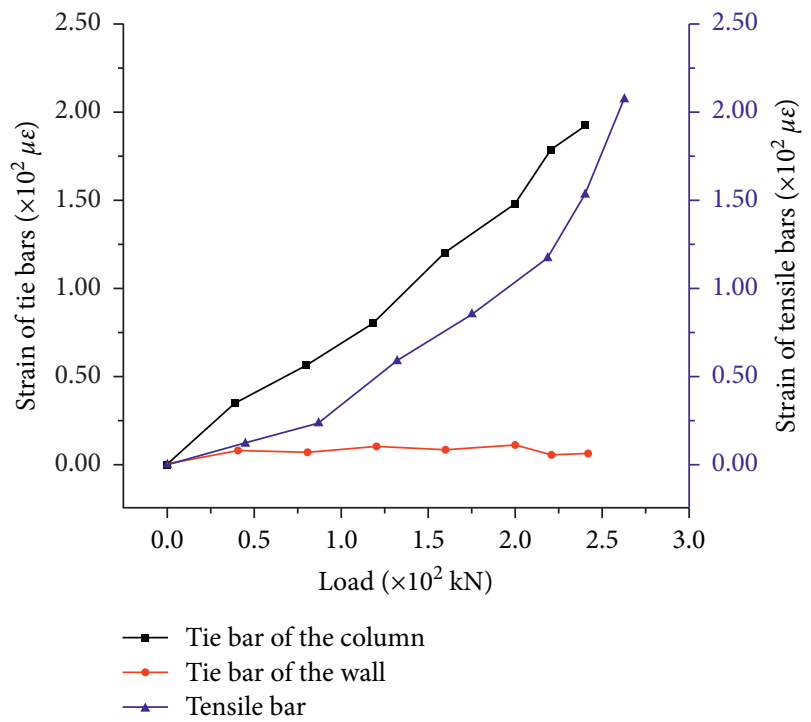

Figure 9: The strain-load curves of the bars.

could be seen that the load-strain curve of the tie bar in the column was basically linear before the failure of the wall. However, the strain of the tie bar at the center of the wall barely changed from the initial loading to failure and the stress was almost $0 \mathrm{MPa}$, which indicated that the out-plane loads were mainly transferred to the column by the tie bars of the column.

The strain-load curve of tensile reinforcement at the midspan of column could be divided into three sections. When the load was less than $80 \mathrm{kN}$, the load-strain curve of tensile reinforcement presented a straight line. After that, the concrete cracked in the tensile zone at the bottom of the wall, resulting in the redistribution of stress. The tensile force originally borne by the concrete was transferred to the steel wire mesh and tensile reinforcement, which caused the increase of their strain; hence, the strain-load curve showed the first turning point. As the loads continued to increase, the strain-load curve of the reinforcement was almost straight until $200 \mathrm{kN}$. Thereafter, the steel wire mesh reached the yield strain, which caused the stress redistribution once again. Thus, part of the tensile stress borne by the steel wire mesh was transferred to the steel reinforcement, and the load-strain curve presented the second turning. The final failure of the wall was due to the stress redistribution caused by the tensile yield of steel wire mesh, which led to the yield of steel reinforcement and the reduction of flexural capacity fleetly. The measured cracking and failure loads of the wall were $80 \mathrm{kN}$ and $240 \mathrm{kN}$, respectively, which could be converted into the uniform load of $6.67 \mathrm{kN} / \mathrm{m}^{2}$ and $20 \mathrm{kN} / \mathrm{m}^{2}$. For the case that the out-plane load in daily application is mainly wind loads, and it could meet the requirement of normal serviceability. In addition, the external wall bore almost no bending moment and the distance between internal and external walls did not affect the flexural capacity, which enlightened us on that concrete with high content of rice husk could be used on the outer wall to take full advantage of the insulation capacity of rice husks.

\subsection{Finite Element Analysis of Flexural Property.} ABAQUS is applied to simulate the flexural bearing capacity test of the wall without a hole, and the steel reinforcement and concrete are set as truss element and solid element, namely, the C3D8R element. In this paper, the distribution mesh seeds with a general size of $100 \mathrm{~mm}$ were set. Except for the inner leaf wall, automatic mesh division was adopted for other components. Due to the irregular shape of the inner leaf wall, the inner leaf wall was split and then mesh division was carried out. In order to analyse the stress distribution of the outer vane wall in the bending test, four layers of mesh were arranged along the thickness of the outer vane wall because of its small thickness. The constitutive model proposed in Section 3.2 was adopted for the compression constitutive model. The constitutive structure of the steel bars in the model adopted the ideal elastoplastic curve 


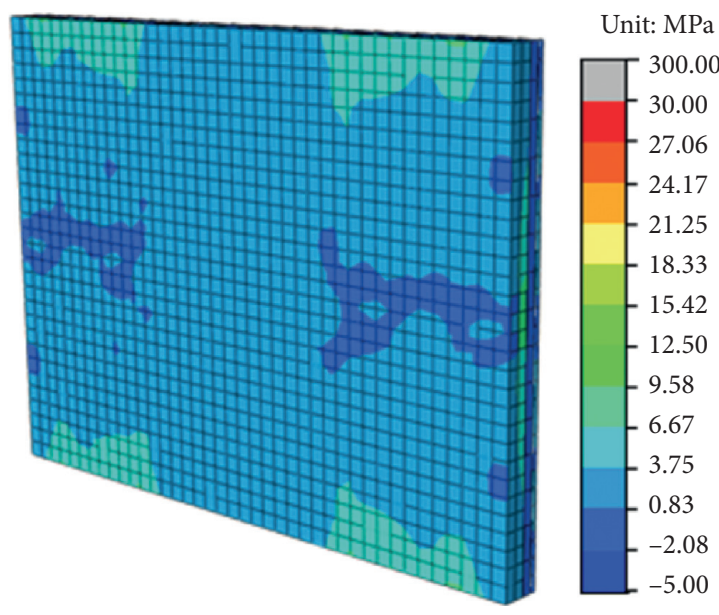

(a)

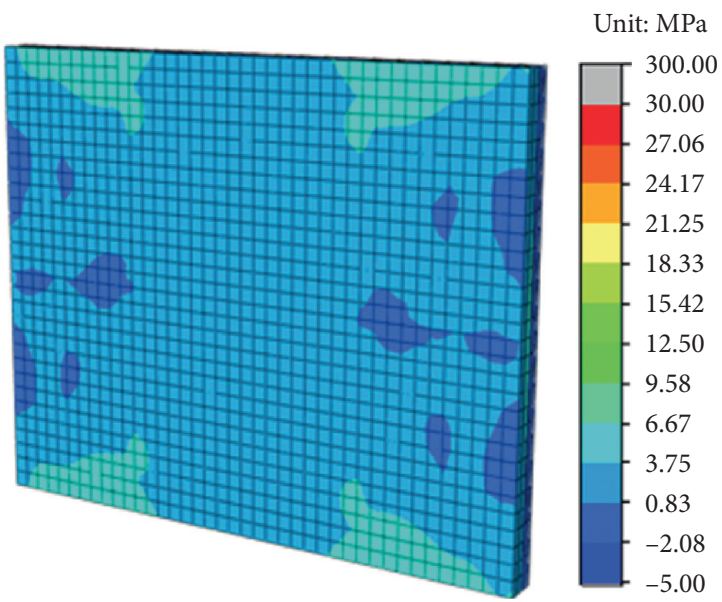

(b)

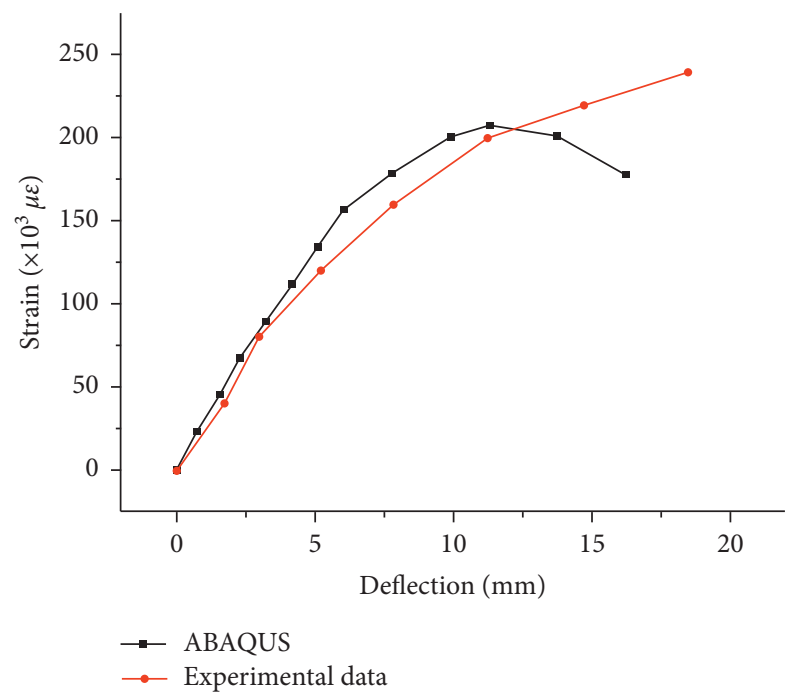

(c)

FiguRE 10: Comparison of the simulation results and the experimental results: the stress nephogram of (a) the four beams loading scheme and (b) the uniformly distributed loading scheme; (c) the load-deflection curves.

constitutive, that is, the stress and strain in the elastic stage were linearly related, and the stress in the plastic stage remained unchanged. The specific parameters of the steel bar are in Section 2.2, and Poisson's ratio is 0.3 . The properties of steel bar could be defined by setting elastic modulus and yield strength in ABAQUS. The boundary condition assumed that the two ends of the specimen were hinged, i.e., $U 1=U 2=U 3=0$.

In order to verify the feasibility of the four beams loading scheme replacing the uniformly distributed loading scheme, the stress condition of these two schemes was studied and is shown in Figures 10(a) and 10(b), which reflected the reliability of this model and analytical method. In addition, the deflection values calculated by the finite element method was slightly lower than that measured in the experiment shown in Figure 10(c), which was resulted from that the concrete strength and stiffness of the wall were lower than the design values.

Tie bars produced certain flexural deformations in the loading process, which might react on the bending capacity of the wall. By changing the layout density, strength, and length of web members of tie bars, the influence of tie bar on the flexural capacity is studied. The load-deflection curves with different parameters of tie bar are shown in Figure 11, where $D(\mathrm{~mm})$ denotes the diameter of tie bars and $h(\mathrm{~mm})$ denotes the length of the web bars. In the experiment, $D=6 \mathrm{~mm}, h=60 \mathrm{~mm}$, and the layout density are $400 \mathrm{~mm} \times 400 \mathrm{~mm}$.

The increase of $D$ and layout density nearly did not affect the flexural capacity of the wall. At the same time, after adjusting the length of web members, the flexural capacity of the wall changed few, which meant that this parameter had hardly affected it. Therefore, the flexural capacity and the different variables of tie bars are related to a certain extent but not crucial, which enlightens us that tie bars only need to meet the construction requirements in the design of this kind of wall.

3.5. Compression Experimental Phenomena and Results of the Wall with a Hole. Until the total load reached $1000 \mathrm{kN}$, a crack with width less than $0.1 \mathrm{~mm}$ appeared at the top of the 


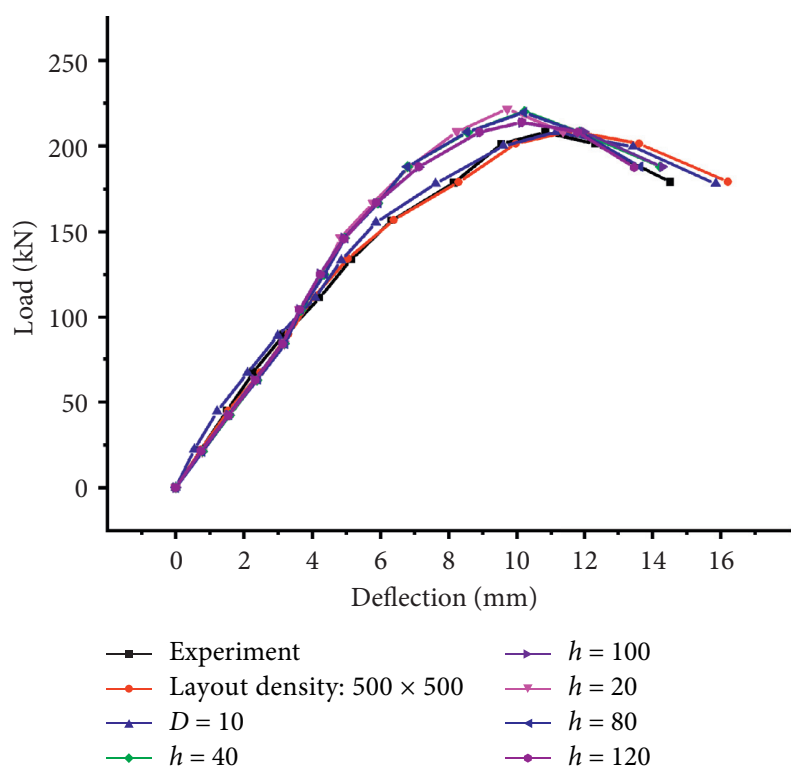

Figure 11: The load-deflection curves of different parameters of the tie bars.

hole of the inner wall due to the ultimate tensile strain of concrete. In addition, vertical microcracks with width less than $0.1 \mathrm{~mm}$ also appeared on the top beam. At the total load of $1400 \mathrm{kN}$, shear-compression diagonal cracks presented at both ends of the top beam of the hole, and several diagonal cracks appeared at the lower end of the beam of the inner wall. As the total load reached $2000 \mathrm{kN}$, new vertical cracks appeared in the connection between the top of the middle column and the thin plate of the inner wall, caused by the uncoordinated deformations of the column and the inner wall. As well, several transverse cracks occurred in the window lintel and cracks in the outer wall became longer and wider. When the total load was up to $2400 \mathrm{kN}$, new vertical cracks were generated in the thin plate among the side and the middle columns of the inner wall, and the vertical cracks also emerged in the edge of the right side of the middle column. At $2600 \mathrm{kN}$, the reinforcements reached yield tensile strain, while the concrete in the compressive zone had not been completely crushed, which indicated that the top beam was destroyed before the constructional column of the inner wall. At $2800 \mathrm{kN}$, the transverse cracks appeared in the middle of the right middle column and developed rapidly until the concrete in the middle of the span was crushed as shown in Figure 12. Finally, the longitudinal reinforcement was yielded, which resulted in the failure of the wall. As shown in Figure 13, by comparing the load-strain curves of concrete and steel bars in the side column with that in the middle column, a conclusion could be drawn that under the vertical uniformly distributed loads, the two middle columns were subjected to more forces.

The compression performance test of the full-scale opening was carried out. Through the observation of the phenomena in the compressive performance test of the specimen and the collection of deformation and strain data, it could be concluded that the failure of the wall with a hole was due to the excessive compressive strain of the concrete near the window of the middle column. The concrete was crushed, which led to the increase of steel bar stress, the yield of steel bar, and the loss of bearing capacity of the wall.

3.6. Compression Experimental Phenomena and Results of the Wall without a Hole. The experimental phenomenon of the wall without a hole is basically the same as that of the wall with a hole, but the ultimate load is $3400 \mathrm{kN}$ instead of $2800 \mathrm{kN}$. With the total load reaching $3400 \mathrm{kN}$, the cracks developed further and the sound of concrete being crushed could also be heard. At this time, the concrete near the central axis in the middle of the top beam continued to be crushed; thereafter, the top beam was damaged as shown in Figure 14.

According to Figure 15, when the wall was destroyed under compression, the maximum tensile strain of the steel reinforcement is about $1500 \mu \varepsilon$ less than the yield tensile strain $(1700 \mu \varepsilon)$. Therefore, the failure of the top beam was not the bending failure in plane of the wall but the compression failure of concrete due to the top beam torsion out-plane restrained. In addition, the vertical deformations of the middle column were greater than that of the side one, which was caused by the flexural deformations of the top beam of the inner wall. As well, the loads were transferred symmetrically to the two middle columns, which was corresponding to the symmetrical form of the structure and the loads.

According to Figure 16(a), from the beginning of loading, the load-deflection curve was almost straight until $2000 \mathrm{kN}$, which was an inflection point due to the development of plastic stage in some parts of concrete. At the same time, Figure 16(b) shows that the inner and the outer walls squeezed each other during the loading process, and the compressive deformation increased with the increase of the loads. 


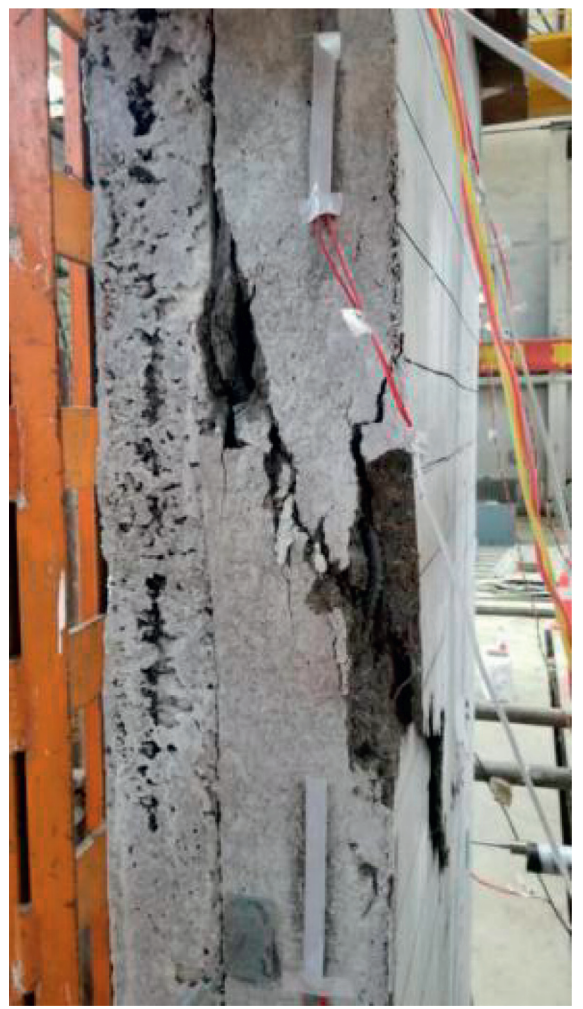

(a)

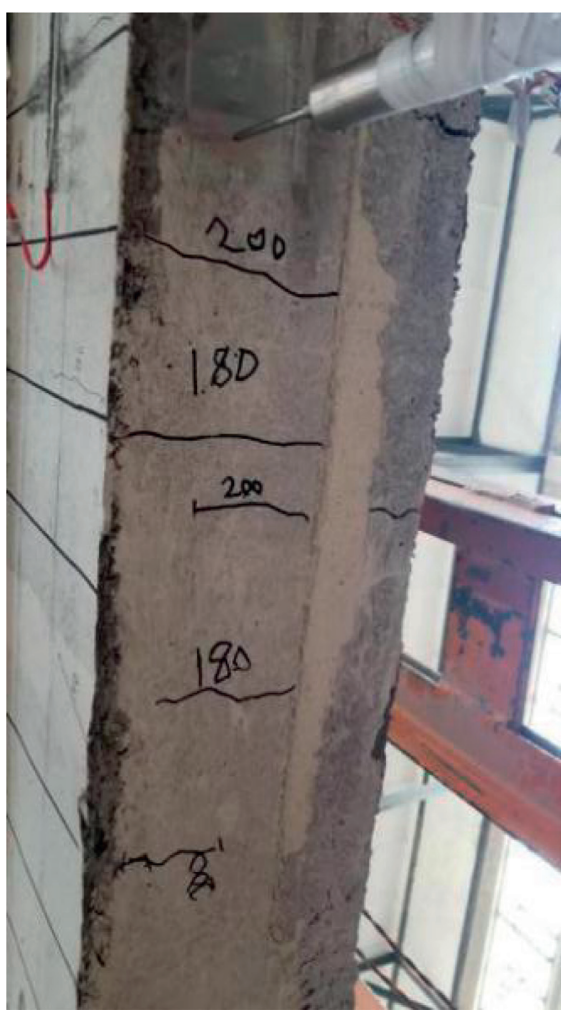

(b)

Figure 12: The experimental phenomena: (a) the damage of the middle column; (b) the cracks at the top of the hole.

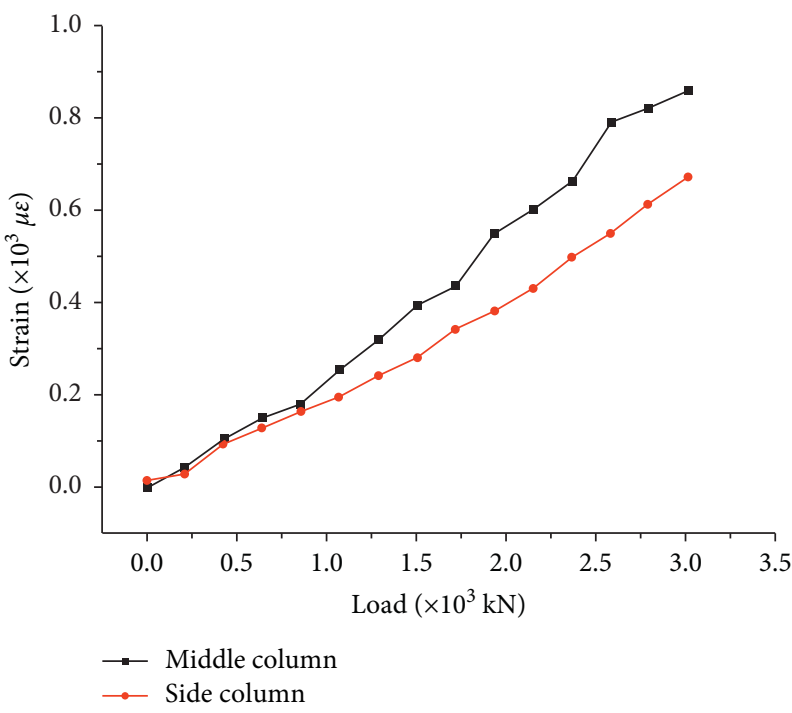

(a)

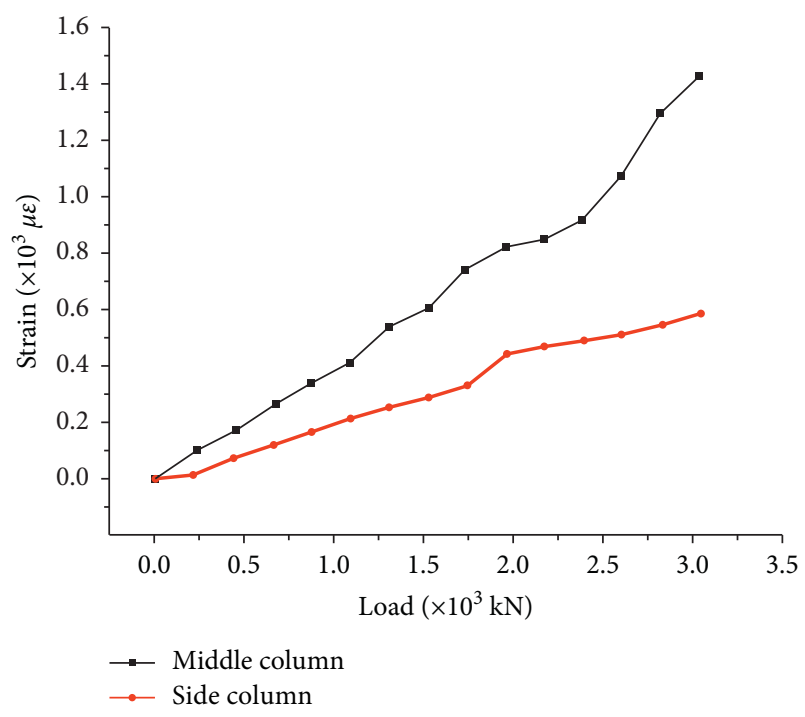

(b)

FIgURE 13: The strain-load curves: (a) steel reinforcements in the inner wall; (b) concrete at the top of the columns.

The compression performance test of full-scale nonopening was carried out, and through the observation of the phenomena in the compressive performance test of the specimen and the collection of deformation and strain data, it could be concluded that the failure of the wall without a hole was due to the fact that the loading beam limited the torsion of the top beam caused by the flexural deformation of the specimen, so that the concrete on the inner leaf wall of the top beam of the specimen was crushed.

3.7. Finite Element Analysis of Compressive Property. Finite element analysis of the compressive property for the wall with and without a hole is also carried out by ABAQUS, 


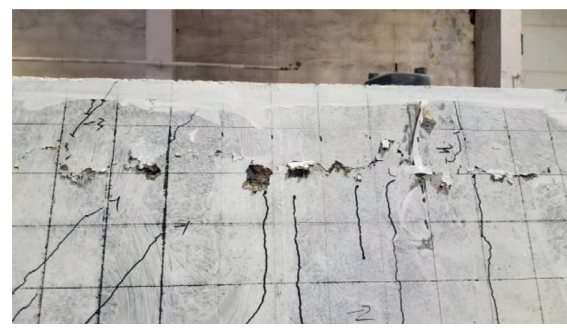

(a)

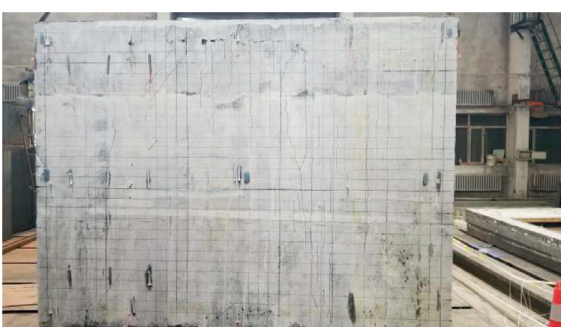

(b)

Figure 14: The experimental phenomena: (a) the damage of interwall top beam; (b) the cracks in the inner wall.

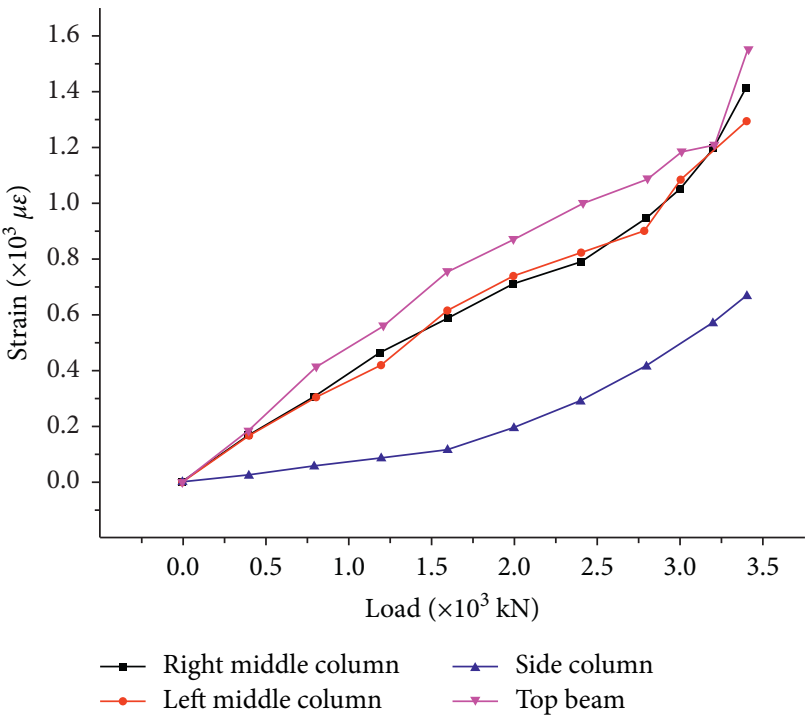

Figure 15: The strain-load curve of reinforcement in the top beam and concrete in the columns.

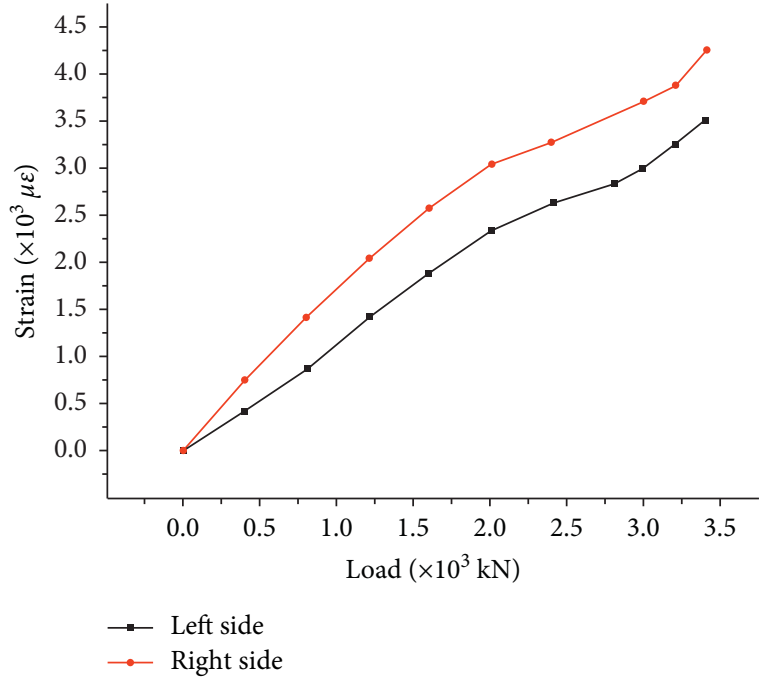

(a)

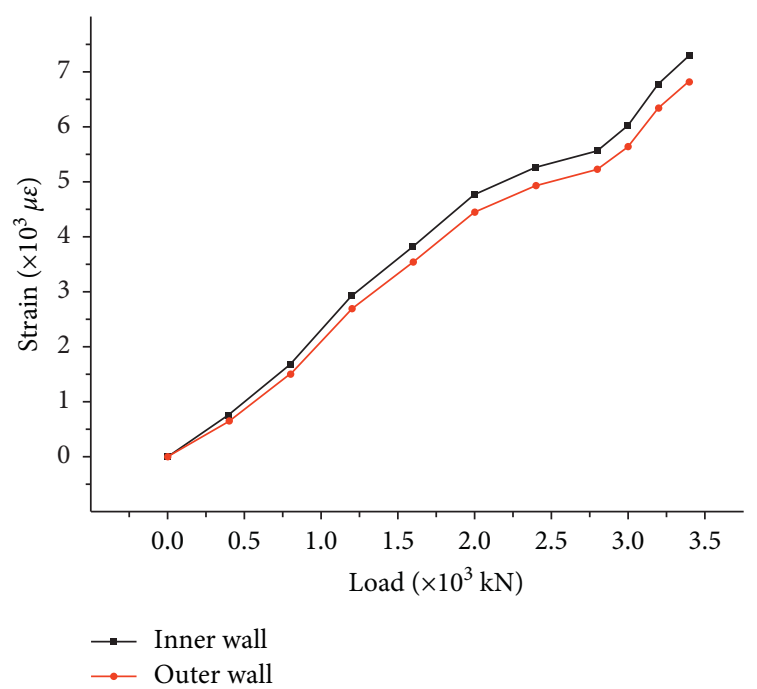

(b)

Figure 16: The comparison of deflections at different parts: (a) the midspan of both sides of the wall; (b) the left side in the middle of the inner wall and the outer wall. 


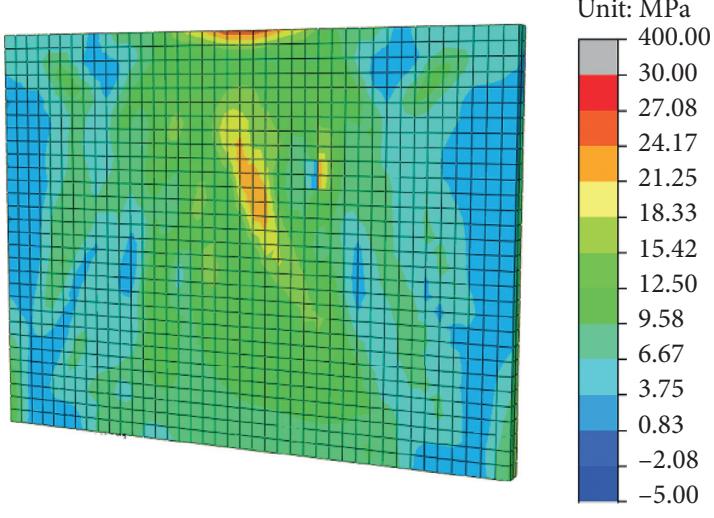

(a)

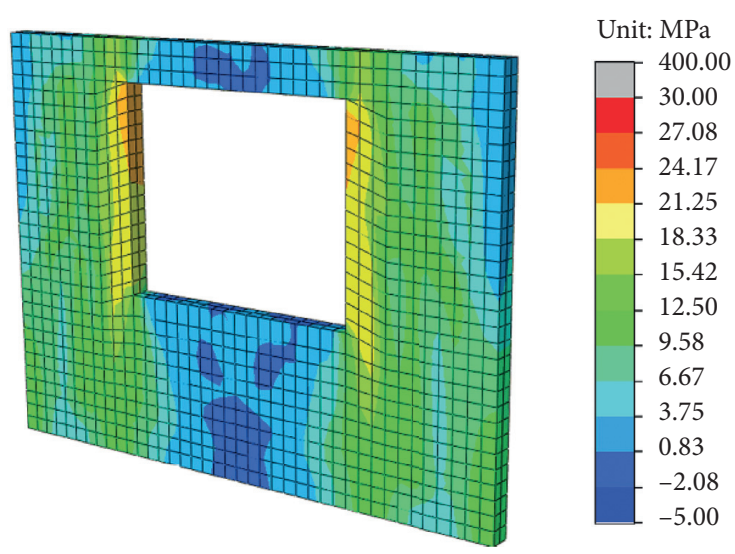

(b)

Figure 17: The stress nephograms of the walls: (a) without a hole and (b) with a hole.

and their stress nephograms are plotted in Figure 17. Comparing experimental strain data with the simulated ones shown in Figure 18, it could be found that the simulated results are basically in agreement with the experimental ones. In addition, it could be inferred from the test and simulation results that the internal force of the middle column was larger than that of the side column, and the load had the phenomenon of "middle-shift" in the simplified mechanical calculation model, that is, after the simplified uniformly distributed load was a concentrated load, the concentrated load at the top of the middle column was larger than that at the top of the side column. The bearing capacity of the side column was not fully exerted when the specimen was destroyed, so the cross section of the side column could be reduced appropriately in the design process. According to this phenomenon, a simplified calculation method of sandwich wall was given in this paper.

The ratio of height to thickness for the inner wall plate is less than that of the column, hence the internal forces are mainly borne by the four inner wall columns, meaning that the uniformly distributed loads acting on the top of the wall can be simplified to the vertical concentrated ones acting on the top of the columns with flanges. When the effect of "middle shift" is not be considered, the vertical deformations of the wall are uniform and the distribution of vertical loads between the side and middle columns is carried out according to their axial stiffness (EA), respectively, just as the following equation:

$$
\frac{F_{1}}{(E A)_{1}}=\frac{F_{2}}{(E A)_{2}}=\frac{F_{3}}{(E A)_{3}}=\frac{F_{4}}{(E A)_{4}}=\varepsilon=\frac{F}{\sum(E A)},
$$

and then the equation (5) could be converted to the following equation:

$$
F=\frac{(E A)_{1}}{\sum(E A)} F+\frac{(E A)_{2}}{\sum(E A)} F+\frac{(E A)_{3}}{\sum(E A)} F+\frac{(E A)_{4}}{\sum(E A)} F .
$$

Subsequently, equations (7), (8), and (9) are inferred to consider the "mid-shift "effect of the loads, so as to make the calculated loads closer to the actual ones:

$$
\begin{aligned}
\frac{F_{1}}{(E A)_{1}}= & \frac{F_{4}}{(E A)_{4}}=\alpha \varepsilon, \\
\frac{F_{1}}{\alpha(E A)_{1}}= & \frac{F_{2}}{(E A)_{2}}=\frac{F_{3}}{(E A)_{3}}=\frac{F_{4}}{\alpha(E A)_{4}} \\
= & \varepsilon=\frac{F}{\alpha(E A)_{1}+(E A)_{2}+(E A)_{3}+\alpha(E A)_{4}} \\
= & \frac{F}{\sum m(E A)}, \\
F= & \frac{\alpha(E A)_{1}}{\sum m(E A)} F+\frac{(E A)_{2}}{\sum m(E A)} F+\frac{(E A)_{3}}{\sum m(E A)} F \\
& +\frac{\alpha(E A)_{4}}{\sum m(E A)} F,
\end{aligned}
$$

where $\alpha$ is the ratio of the axial force to the bearing capacity when the wall is failed, $F_{1}$ and $F_{4}$ are the concentrated loads acted on two side columns, and $F_{2}$ and $F_{3}$ act on two middle columns. And, the coefficient $m$ is equal to 1 or $\alpha$.

Since there is no instability failure of the wall and no bending failure of the beam, the bearing capacity of the ecological composite sandwich wall under axial compression can be calculated based on the following equation [30]:

$$
N \leq \varphi \sum \beta\left(f_{c} A_{z}+f_{y}^{\prime} A_{s}\right),
$$

where $N$ is the design value of the axial force of the wall; $f_{c}$ is the axial compressive strength of column concrete; $f_{y}$ is the design value of compressive strength of reinforcements; $A_{z}$ is the sectional area of the column with flange; $A_{s}$ is the area of the longitudinal reinforcements of the column; and $\varphi$ is the stability coefficient of the wall.

Due to the complex structure of the inner wall, the computing method of $A_{z}$ refers to the determination method of flange width of shear wall with flange in GB 50010-2010 [30]. Then, the calculation results based the proposed bearing capacity formula and the test values are listed in Table 3. It can be seen that the calculated results of the equation are close to the experimental results, which can be 


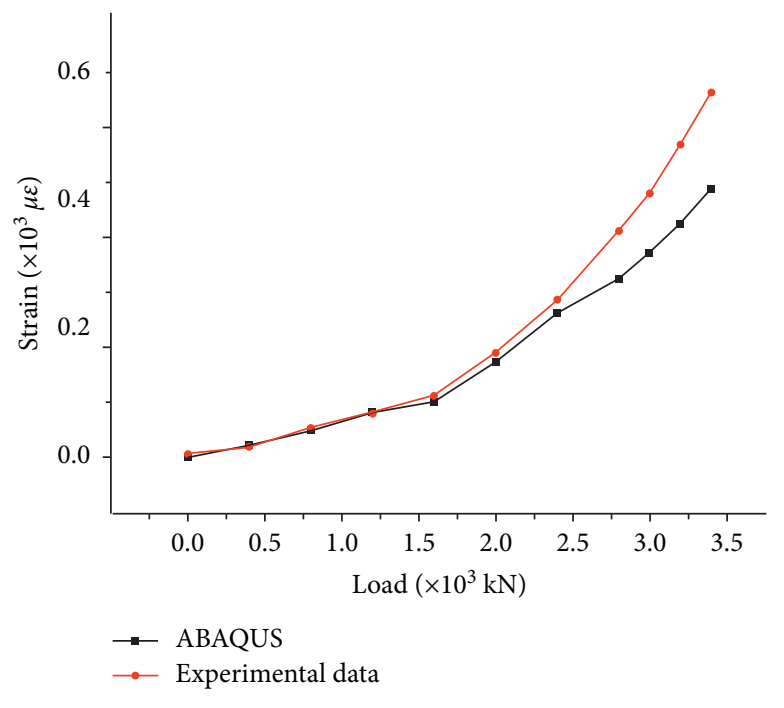

(a)

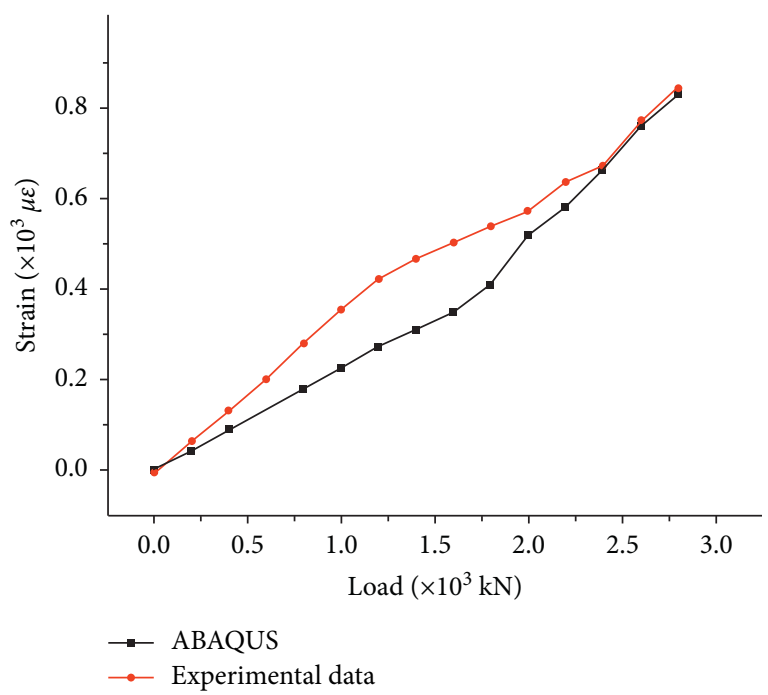

(b)

Figure 18: Comparison of the strain-load curves of experiment and of calculated by finite element method: (a) the top of the side column; (b) the middle in the right side of the hole.

TABLe 3: The comparison between the calculated results and the experimental results.

\begin{tabular}{lccc}
\hline Experimental wall & Formula value $N_{u}^{\prime}(\mathrm{kN})$ & The test results $N_{u}(\mathrm{kN})$ & $\left|N_{u}^{\prime}-N_{u} / N_{u}\right|$ \\
\hline The wall with a hole & 3591 & 3400 & 0.056 \\
The wall without a hole & 2871 & 2800 & 0.025 \\
\hline
\end{tabular}

used as a reference for the design of ecological composite sandwich wall.

\section{Conclusion}

In this paper, the mechanical properties of RHRC were studied and analyzed. Subsequently, the experiments and the numerical simulations of the full-scale eco-composite sandwich wall on the flexural behavior and two full-scale sandwich walls on the compressive properties were carried out, accompanied by the following conclusions:

(1) The compressive strength of RHRC reduces with the rises of rice husk content and decreases first and then increases with the growth of recycled aggregate replacement rate. The stress-strain curves of RHRC are in agreement with the constitutive curves proposed by Guo, and the relationship of the parameter b, rice husk content $m$, and recycled aggregate substitution rate $p$ is established by data fitting.

(2) The flexural capacity of composite sandwich walls is very high, and there are three stages during the whole loading process. The reasons of ultimate failure are mainly caused by the yield of tensile steel reinforcement and the excessive deflection of walls. In addition, the bending moment of the wall is mainly borne by the inner wall, so more thermal insulation materials could be added into the outer wall.
Meanwhile, the simulation results show that it is feasible to replace the uniform load with four loading beams and that tie bars can bear part of the bending moment but have no obvious effect on the flexural capacity.

(3) The ecological composite sandwich walls have good compression resistance and no instability failure. The failure reason of the wall with a hole was that the excessive compressive strain of concrete led to the yield of steel reinforcements, and then the wall lost the bearing capacity. As for the wall without a hole, it was that the top beam torsion out-plane restrained. Furthermore, based on the simulation results, a simplified calculation formula of vertical bearing capacity considering "midshift": effect is proposed, and the calculation results are consistent with the experimental ones.

\section{Data Availability}

The data used to support the findings of this study are available from the corresponding author upon request.

\section{Conflicts of Interest}

The authors declare that there are no conflicts of interest regarding the publication of this paper. 


\section{Acknowledgments}

The authors would like to express their gratitude to Wenmiao $\mathrm{Du}$ for carrying out the excellent bridge model experiment and giving the experimental data in her thesis.

\section{References}

[1] J. Opon and M. Henry, "An indicator framework for quantifying the sustainability of concrete materials from the perspectives of global sustainable development," Journal of Cleaner Production, vol. 218, pp. 718-737, 2019.

[2] F. Pacheco-Torgal and J. A. Labrincha, "The future of construction materials research and the seventh UN Millennium Development Goal: a few insights," Construction and Building Materials, vol. 40, pp. 729-737, 2013.

[3] R. Islam, T. H. Nazifa, A. Yuniarto, A. S. M. Shanawaz Uddin, S. Salmiati, and S. Shahid, "An empirical study of construction and demolition waste generation and implication of recycling," Waste Management, vol. 95, pp. 10-21, 2019.

[4] K. Sadi, A. Abdullah, M. Navazandeh Sajoudi et al., "Reduce, reuse, recycle and recovery in sustainable construction waste management," in Advanced Materials Research, pp. 937-944, Trans Tech Publications, Stafa-Zurich, Switzerland, 2012.

[5] S. Guy, "Sustainable buildings: meanings, processes, users," Built Environment, vol. 28, no. 1, pp. 4-10, 2002.

[6] J. K. Borges, F. Pacheco, B. Tutikian, and M. F. de Oliveira, "An experimental study on the use of waste aggregate for acoustic attenuation: EVA and rice husk composites for impact noise reduction," Construction and Building Materials, vol. 161, pp. 501-508, 2018.

[7] E. Ahn, D. Yeom, and K.-I. Lee, "Experimental research on the indoor environment performance of complex natural insulation material: carbonized rice hull and rice hull," Journal of Asian Architecture and Building Engineering, vol. 16, no. 1, pp. 239-246, 2017.

[8] A. Briga-Sá, D. Nascimento, N. Teixeira et al., "Textile waste as an alternative thermal insulation building material solution," Construction and Building Materials, vol. 38, pp. 155-160, 2013.

[9] T. Thamae, R. Marien, L. Chong, C. Wu, and C. Baillie, "Developing and characterizing new materials based on waste plastic and agro-fibre," Journal of Materials Science, vol. 43, no. 12, pp. 4057-4068, 2008.

[10] V. A. Mymrin and A. J. Vázquez-Vaamonde, "Red mud of aluminium production waste as basic component of new construction materials," Waste Management and Research, vol. 19, no. 5, pp. 465-469, 2001.

[11] R. Taurino, P. Pozzi, G. Lucchetti et al., "New composite materials based on glass waste," Composites Part B: Engineering, vol. 45, no. 1, pp. 497-503, 2013.

[12] V. A. Leshina and A. L. Pivnev, "Ceramic wall materials using glass waste," Glass and Ceramics, vol. 59, no. 9/10, pp. 356-358, 2002.

[13] R. Ji, S. Wu, C. Yan et al., "Preparation and characterization of the one-piece wall ceramic board by using solid wastes," Ceramics International, vol. 43, no. 12, pp. 8564-8571, 2017.

[14] D. Waldmann, V. Thapa, F. Dahm et al., "Masonry blocks from lightweight concrete on the basis of Miscanthus as aggregates," in Perennial Biomass Crops for a ResourceConstrained World, pp. 273-295, Springer, New York, NY, USA, 2016.

[15] L. N. Hou and G. Jing, "Mechanical properties and calculation model of eco-composite wall," in Applied Mechanics and
Materials, pp. 836-839, Trans Tech Publications, Stafa-Zurich, Switzerland, 2013.

[16] E. Aprianti, P. Shafigh, S. Bahri, and J. N. Farahani, "Supplementary cementitious materials origin from agricultural wastes - a review," Construction and Building Materials, vol. 74, pp. 176-187, 2015.

[17] B. Middendorf, J. Mickley, F. Martirena et al., "Masonry wall materials prepared by using agriculture waste, lime, and burnt clay," in Masonry: Opportunities for the 21st CenturyASTM International, West Conshohocken, PA, USA, 2002.

[18] J. Zach, J. Brozovsky, and J. Hroudova, "Investigation of antinoise absorptions walls development with utilization of waste from agriculture," in IABSE Symposium Bangkok 2009. Sustainable InfrastructureEnvironment Friendly, Safe and Resource EfficientInternational Association for Bridge and Structural EngineeringChulalongkorn University, ThailandAsian Institute of Technology, Khlong Nueng, Thailand, 2009.

[19] N. Padkho, "A new design recycle agricultural waste materials for profitable use rice straw and maize husk in wall," Procedia Engineering, vol. 32, pp. 1113-1118, 2012.

[20] A. Antunes, P. Faria, V. Silva, and A. Brás, "Rice husk-earth based composites: a novel bio-based panel for buildings refurbishment," Construction and Building Materials, vol. 221, pp. 99-108, 2019.

[21] J. António, A. Tadeu, B. Marques, J. A. S. Almeida, and V. Pinto, "Application of rice husk in the development of new composite boards," Construction and Building Materials, vol. 176, pp. 432-439, 2018.

[22] L. Jiesheng, W. Lingling, D. Yi et al., "Research on the basic properties of rice husk wall materials with different grain," Journal of Wuhan University of Light Industry, vol. 36, no. 3, pp. 92-95, 2017, in Chinese.

[23] Z. Jian, "Research on stress state and failure criteria of rice husk mortar composite wallboard," Masters Thesis, Harbin Institute of Technology, Harbin, China, 2016, in Chinese.

[24] MOHURD GB/T 50152-2012, Standard Methods for Testing of Concrete Structures, China Architecture and Building Press, Beijing, China, 2012, in Chinese.

[25] MOHURD GB/T 50081-2002, Standard for Test Method of Mechanical Properties on Ordinary Concrete, China Architecture and Building Press, Beijing, China, 2002, in Chinese.

[26] X. Jianzhuang, L. Ao, and D. Tao, "Evaluation of $\mathrm{CO}_{2}$ emission during life cycle of recycled concrete," Journal of Southeast University (Natural Science Edition), vol. 46, no. 5, pp. 1088-1092, 2016, in Chinese.

[27] G. Yuxing, W. Jun, X. fenlian et al., "Carbon emission assessment of green production of ready-mixed concrete," Concrete, vol. 1, pp. 110-112, 2011, in Chinese.

[28] T. Telford, Comite Euro-Internetional du beton CEB-FIP model code 1990, Design code, 1993.

[29] Z. Guo, Strength and Deformation of Concrete, Tsinghua University, Beijing, China, 1997.

[30] G. B. MOHURD, 50010-2010, Code for Design of Concrete Structures, China Architecture and Building Press, Beijing, China, 2010, in Chinese. 